\title{
Is there Trust in the Scandinavia of India? On Understanding Generalized Trust in Kerala
}

\author{
Magnus Olof Karlsson ${ }^{1}$ \\ ${ }^{1}$ Ersta Skondal Bracke University College, Sweden \\ Correspondence: Magnus Olof Karlsson. E-mail: magnus.karlsson@esh.se
}

Received: April 18, 2018

doi:10.5539/ass.v14n9p16
Accepted: May 4, $2018 \quad$ Online Published: August 31, 2018

URL: https://doi.org/10.5539/ass.v14n9p16

\begin{abstract}
Kerala is considered as the most social advanced state of India, and can in many respects be seen as "the Scandinavia of India". But despite the fact that Kerala scores high on the Human Development Index as well as many other welfare indicators, there are arguments that generalized trust — when people trust most people even if they do not know them - is low. In this text, Kerala is sometimes compared to Sweden, one social-democratic well-developed welfare state in Scandinavia, and it is argued that the family constellations, the historical relations between the working-class movement, the employers and the government, as well as the extensive remittance economy characterising Kerala, have reduced trust through creating large inequalities and decreasing civil engagement.
\end{abstract}

Keywords: trust, social capital, Kerala, welfare, modernization

\section{Introduction}

The Indian state of Kerala has often been seen as a "model" for social development, as being the most socially advanced state in the country, and in such parts unparalleled in low income societies (Heller, 1999; Veron, 2001; Sen, 2005). Kerala has been referred to as "the Scandinavia of India" (Törnquist \& Harriss, 2017; Karlsson, 2018), and Jean Drèze and Nobel Prize-winner Amartya Sen (2002) underline that the significance of Kerala's experience is often underestimated in national discussions. At first glance, this model state shows most of the characteristics of a society where important social values such as social capital and trust would thrive. For that reason, the results from the World Value Survey (WVS), covering 100 countries and most often referred to when discussing trust in societies (e.g. Rothstein \& Uslaner, 2005; Newton \& Zmerli, 2011), show that only 1.6 per cent of the respondents ( $\mathrm{n}=192)$ agree with the statement "Most people can be trusted" while 98.4 per cent think that they "Need to be very careful". The corresponding result for all India $(n=4078)$ is 16.7/77.9 per cent, and for Sweden ( $\mathrm{n}=1206)$, one of the most well-developed welfare democracies in the world and with many similarities to Kerala (see below), it is 60.1/37.2 per cent. Although the number of respondents was small and more extensive research needs to be done, there is reason to believe that generalized trust, mirrored by the notion that most people can be trusted, is lacking in Kerala.

In this text, I try to present a theoretical understanding of the pattern of trust in Kerala, in some respects by comparing Kerala to Sweden. I identify three possible explanations for the combination of the relatively high scores on human development and the dramatically low scores on trust displayed for Kerala by the WVS. I do this by reviewing existing research literature as well as public reports describing the situation primarily in Kerala, but also in other societies, such as Sweden. Although English texts are primarily addressed, arguments have been carefully evaluated in dialogue with scholars in India and Sweden.

First, I argue that the family situation in Kerala and Sweden are different; although changing, the extended family have a vital role in Kerala, while the nuclear family, or to some extent even the single households, have since long shaped the situation in Sweden. This, including the fact that extended families still have a social security situation in Kerala, gives reason to believe that trust is characterised by particularity rather than generality in this Indian state. Second, I argue that although the working-class movement, organised by the communists, was successful in gaining political power and in promoting/implementing public welfare in the 1950's and later, it did not succeed in creating broad consensus agreements between employers and employees. Thus, opportunities for collective action and collaboration in the labour market- important to strengthen generalized trust in society-were lost. Third, I claim that modernisation processes in Kerala, including the 
remittance economy, are eroding trust by hampering local civil engagement and increasing inequality. Finally, I touch upon the understanding of corruption in Kerala, since corruption is often seen as closely connected to trust, and since the picture of corruption is scattered. In my arguments, I address that even if generalized trust is decreasing in Kerala, forms of particularised trust in friends, family and civil society organisations, including unions and religious groups, might be well developed; the extended family still plays an important role in society, and Kerala is well-known for its vibrant civil society (e g Heller, 1999).

\section{On Trust}

Trust is considered by many scholars as a central social variable, and as social glue that holds associations, companies and societies together (Fukuyama, 1995; Seeligman, 1997; Wallman Lundåsen \& Trägårdh, 2013). Trust is seen as promoting democracy, economy, health, happiness and quality of life, as well as reducing corruption, crime, and economic transaction costs (Rothstein \& Stolle, 2008; Leung et al., 2010; Wollebaek, Wallman Lundåsen, \& Trägårdh 2012). Although much remains to be explored, most scholars connect trust with democracy and wealth, and high social trust is often found in well-developed democracies with extensive welfare systems - e.g. the Scandinavian countries - that also score high on the Human Development Index (HDI) (e.g. Rothstein \& Uslaner, 2005).

Trägårdh (2013) argues that interest in trust - and the preoccupation with its fragility - has a long history. He reminds us of how prominent scholars such as Marx, Durkheim, Simmel, Weber and Tönnis all discussed how modernisation weakened the ties of the organic community, and thereby threatened trust among people. Later on, Habermas [1996] and Putnam [2000] discussed modernisation as threatening the "lifeworld" and social capital in society. Nobel Prize-winner Elinor Ostrom states that "The very condition for a successful market economy and democracy is that a vast number of people relate in a trustworthy manner when dealing with others-many of whom not do not know one another and cannot incorporate repeated interaction or a network-to achieve collective actions of various scales." (Ostrom \& Ahn 2007, p. 14)

Social trust, a concept still in the making, is often divided into particularised trust (we trust specific persons that we know, e.g. family members) and generalized trust (most people can be trusted) (e.g. Newton \& Zmerli, 2011; Wollebaek, Wallman Lundåsen, \& Trägårdh, 2012). Although it can be hard to tell where particularised trust ends and where generalized trust starts (Sztompka, 1999), this difference appears to be important when understanding societies. Most attention has so far been given to generalized trust; it facilitates transactions, collective action and democratic decision-making. In high-trust societies people are willing to take a leap of faith to achieve things with others they do not know.

The amount and patterns of social trust differ between societies: in highly developed democracies characterised by secular-rational values, such as many countries in Western Europe, more than half the entire population think that most people can be trusted, while this generalized social trust is much lower in less developed, more traditional countries, such as many African and South American countries (Rothstein \& Uslaner, 2006; Inglehardt \& Welzel, 2010). This does not mean that particularised trust cannot prosper in traditional (Ostrom \& Ahn, 2007; Onyx \& Bullen, 2016) - or in secular-rational! - societies (Newton \& Zmerli, 2011).

Rothstein and Uslaner (2005) claim that the most widely cited explanations for enhancing generalized social trust focus on participation in voluntary associations [see for example Putnam 2000], but question this by stating that this explanation fails in empirical tests. Instead they suggest that equality-in their case economic equality and equality of opportunity - is a key factor when understanding trust (see also Wilkinson \& Pickett, 2009). Rothstein and Stolle $(2002,2008)$ give yet another explanation: the structure and characteristics of contemporary government institutions are essential factors when understanding the origin of trust. The procedural fairness of such institutions makes citizens feel safe, protected, and as equal to each other in relation to the state.

\section{Trust and Social Capital}

Trust among people is often closely connected to social capital (Putnam, 1995; Portes, 1998). Such capital is strengthened when people engage in networks, associations and organisations in order to accomplish things together as a "we". In this, they create mutual expectations and norms, they form new and stronger social ties, and they develop social trust towards each other. Putnam (1995) defines social capital as " $\ldots$ features of social organisation such as networks, norms, and social trust that facilitate coordination and cooperation for mutual benefit." In this, Putnam (2000) distinguishes between bonding social capital, which ties existing groups together, and bridging social capital, which overlaps barriers, and creates connections between people within groups (see also Narayan, 1999). Even if many scholars argue (e.g. Igarashi et al., 2008) otherwise, bonding social capital is often seen as having negative effects on society as a whole (although possible positive effects for group members) by creating in-group loyalty, but possibly also out-group antagonism, while bridging social capital is seen as 
tying a society together. It comes as no surprise that generalized trust and bridging social capital have been linked together (e.g. van Oorschot, Arts \& Gelissen, 2006)

The understanding of trust and social capital has its roots in the United States, but has also been extensively researched in the Scandinavian countries (e.g. Rothstein \& Stolle, 2008; Wollebaek, Wallman Lundåsen \& Trägårdh, 2012). In trying to understand trust in Kerala, we turn to Sweden as a documented high-trust society that has striking similarities to this Indian state, but also important differences.

\section{Kerala and Sweden - Some Striking Similarities}

Kerala is considered as the state having the most well-developed welfare systems in all India. Suryanarayana, Ankush and Agrawal (2011) conclude that Kerala scores higher than any other state in India on all Human Development Index (HDI) indicators; income per capita (5263 \$, 3337 \$ in all India) and life expectancy (74 years, 63.5 in all India) as well as mean years of schooling (6.2, 4.1 in all India) and school life expectancy (11.3, 9.6 in all India). In addition, Kerala has the lowest infant mortality rate (6 in Kerala, 41 for all India) and the highest literacy rate $(97.9 \%$ for women and $98.7 \%$ for men in Kerala, compared to $68.4 / 85.7 \%$ in all India) (NFHS-4). This means that the infant mortality rate in Kerala is on a par with the United States (6) (worldbank.org), and that the literacy rate is not only world class, but equal between men and women.

Given these and similar indicators, Kerala can be seen as being to India what Sweden, with its well-established social democratic welfare state and world class scores on HDI (Human Development Report, 2013), is to the world. And the similarities between the two societies do not stop at HDI numbers: both societies share a history of welfare ambitions where health, welfare and education should be not only for the elite, but also for the common people, rooted in the working-class movement. In addition, both Kerala and Sweden have rich (although different) civil societies, including strong labour unions (Heller, 2001; Drèze \& Sen, 2002; Lundström \& Wijkström, 1996; Svedberg \& Lundström, 2003), and close collaboration between state and civil society (John \& Chathukulam, 2002; Vero, 2001).

Kerala is, however, part of a developing country, while Sweden has been one of the wealthiest countries in the world for a long time. This leads to differences which are important to be aware of when discussing trust. First, wealth is considerably higher in Sweden than in Kerala - income per capita is almost ten times as high. Second, the distribution of wealth is different. Although both Kerala and Sweden have traditionally been seen as having small gaps between rich and poor, both societies have faced changes in recent years, leading to greater inequalities. While Sweden has faced the largest growth in inequality of all Organisation for Economic Cooperation and Development (OECD) countries between 1985 and the early 2010 (oecd.org), the Gini coefficient (lower numbers indicate economic equality) in Sweden (0.27) was still one of the lowest in the world in 2010 (worldbank.org). In Kerala, on the other hand, this Gini coefficient rose from 0.34 (0.33 for all India) in 1983 to 0.47 ( 0.37 for all India) in 2010 - indicating not only a drastic increase, but also new and severe inequalities. Third, corruption, often seen as essential to understand state capacity-building, social capital and trust, is considered to be much higher in Kerala than in Sweden. In this case, comparable figures are hard to find, but according to Transparency International (transparency.org), which ranks the "cleanest" countries in the world, Sweden is placed at no. 6 and India at no. 81 out of 180 countries. Kerala, however, turns out to have the lowest corruption rates in India (Kenny 2015).

\section{Three Arguments for Lack of Trust in Kerala}

In below, three arguments for lack of generalized trust in Kerala are presented and discussed. In the analysis, the situation in Kerala is compared to the one in Sweden.

Argument 1: The collective family traditions in Kerala build particularized rather than generalized trust.

Understanding family constellations in India is seen as a complex task (e g Niranjan, Nair, \& Roy, 2005) and lies far beyond the scope of this text. Instead, my first argument is limited to that particularized trust - trusting people you already know - is higher in societies with an extended family culture and strong family ties, while generalized trust - most people can be trusted - is higher in societies with a nuclear family tradition, and with many single-member households.

Based on Putnam (2000) and others, Trägårdh (2018) argues that a society where the family culture is characterized by hierarchy and bonds of loyalty, leaves little room for citizenship, public rights and obligations and generalized trust. Comparing trust to a globe with a "hot" center and a "cooler" surface, Trägårdh argues that the center contains family and close friends, while the outer parts of the globe contains people in general and public society. While clan and family based societies has hot trust with a short radius, more individualistic oriented countries, where Sweden can be seen as one extreme, has "cooler" trust - with a longer radius. 
In recent years, several scholars have paid attention to this "radius of trust". Delhey, Newton and Welzel (2011) show that the radius of trust differs considerably between different societies. Referring to the WVS, they display that the radius of trust is, for example, considerably shorter in India (no specific information on Kerala) than in Sweden. Put differently: general trust seems to be more "general" in Sweden than in India. They conclude that relative to the standard measure, radius-adjusted trust is lower in Asian societies, while protestant countries in the West keep their position as high-trust societies. van Horn (2015) displays, again based on WVS results, that the more individualistic the culture of a society is, the broader the radius of trust within this society will be.

But is Kerala more family-oriented than for example Sweden? Due to the complexity of understanding family constellations in India, the information about family living conditions are scattered. According to the last Census (2011), 68 per cent of the households in Kerala contained one couple, while 14 per cent contained two couples (indicating joint families or likewise). The NHFS-4 (2015/16) reports that $55.5 \%$ of the keralian population lives in nuclear families, while Niranjan, Nair \& Roy (2005) shows that $24 / 27$ per cent of the urban/rural households in Kerala contain joint families. They show that only a very small percentage $(1.8 / 2.8 \%)$ is single-members households (while Zachariah (2017) claims this share being $3.25 \%$ ). Contrasting this, Sweden Statistics (SCB 2014) shows that 47.1 per cent of all households in Sweden were single couple households (with or without children), while no less than 37.7 per cent were single-member households. Joint families and similar was insignificant. In all, the family situation in Kerala appears to be more collective/traditional, while it is much more individualistic/modern in Sweden. In their influential text identifying traditional/secular-rational and survival/self-expression values, Inglehart and Welzel (2010) argues that "Societies near the traditional pole [in this case: India] emphasize the importance of parent-child ties and deference to authority, along with absolute standards and traditional family values..." (p. 563) There are good reasons to argue that the situation in Kerala is more similar to the one in India than that in Sweden, that traditional family values are linked to particularized trust, and hence that particular trust is (still) favored over generalized trust in Kerala.

\section{Argument 2: Communists in Kerala Limited Trust by being Successful in Struggling but not in Governing}

In understanding trust in Kerala, one also has to consider the working-class movement activities that took place in the mid- $20^{\text {th }}$ century, leading to social democratic reforms, including better working conditions, redistribution of resources and public welfare efforts. My second argument when trying to understand the low levels of generalized trust in Kerala is that although the working-class movement gained power both in Kerala and Sweden during this time, trustful relations between the capital and the workers were established in Sweden, but not in Kerala.

In the 1940s, the Communist Party of India (CPI) was able to summon unions, cast reform movements, farmer associations and student groups in an attack on the feudal institutions in what was to become Kerala. The growing working-class movement that evolved was built on a long tradition of social movements in the area - the first labour union in the area was established in 1922 (Heller, 1999). When the Congress Party won solid majorities in all other states in the Indian general election in 1957, the communists came to power in Kerala. This was the first election ever held in the new state of Kerala, and the first time in history that any communist party had come to power through a democratic election (this is interesting, since many scholars claim that communism holds back generalized trust, while such trust thrives under democracy). Although power was taken away from them in 1959 by the instrument of the President's rule in India, that gave the Communist party not only time to launch a land reform programme and a reform of the educational system, but also initiated a long era of domination In Kerala, where they have alternated with the Congress party to be in power (Heller, 1999; Heller, 2001; Kulke \& Rothermund, 2002; Harriss \& Törnqvist, 2017).

The history of communism in Kerala covers many aspects relevant to understanding trust, including the history of social mobilisation in the pre-Kerala areas as well as how working-class masses were united to fight landlordism, casteism and the existing labour systems. Here, another aspect is however focused, namely the dilemma the communists faced when they got into power after the election in 1957. Initially, they acted on behalf of the lower classes, fighting to improve their conditions. But coming into power-should they govern or struggle?

The Social Democrats in Sweden faced a similar dilemma in the early $20^{\text {th }}$ century; labour unions were formed, demanding better conditions, and met by an association of employers during the first years of the century. As pointed out by Musial (1999), sincere collective bargaining could however not be carried out between workers and employers until there was a balance of power between them, which happened in the 1930s. In 1938 (the same year as the pre-Kerala working-class movement was consolidated by a general strike!), both parties finally reached an agreement — the Saltsjobaden Agreement—after heavy pressure from the social democratic Swedish 
government. This agreement was broad, characterised by consensus rather than conflict, and was built upon future expectations of collaboration between employers and employees, in order to reach mutual success. The Saltsjobaden agreement was not the first of its kind - for example, similar negations had been held in Denmark almost 40 years earlier - but it indicated a substantial change in the relations between employers and employees in Sweden, where both parties had an interest in peace within the labour market and, through that, economic growth. Musial (1999) concludes that these collective, consensus-oriented negotiation processes that took place in both Sweden and Denmark contributed to the consensual democracy that is today called the Scandinavian Model (see also Kettunen, 2014).

When scholars (e.g. Heller, 1999) describe the development of the labour market in Kerala from the 1930s to the 1990s, this kind of broad and consensus-oriented Saltsjobaden agreement is nowhere to be found. Over the years, there has been a decline in working-class militancy, and agreements are regularly made between employers and employees, but they are more specific and less consensus/collaboration oriented. Instead, Heller concludes that “... uneven development of the trade union movement, fierce inter-union rivalries, and the sheer insecurity of employment encourage opportunism rather than cooperation." (p. 195) It is noteworthy that while the government in Kerala has played an important role on the labour market, one reason for the successful establishment of the Saltsjobaden agreement in Sweden was that neither the employers nor the employees wanted the government to interfere. It can be argued that this forced the actors in the Swedish labour market to collaborate and to trust each other in order to avoid government interventions that were unwanted by all central actors.

To conclude, although Kerala and Sweden share a history of progressing from very poor to relatively well-developed under the influence of social democracy, they differ in that communists in Kerala roughly speaking applied a conflict model based on a zero-sum game (what is gained by the workers is lost by the employers), while the social democratic unions in Sweden chose consensus and reached a central agreement built on collaboration between the parties - creating a positive-sum game. It can be assumed that such an agreement was built on the belief of collective action and on existing generalized trust, but also that it placed great expectations of trust on the labour market. In this, broad welfare solutions covering all citizens applied by the social democratic government in Sweden kept different interest groups together, while more targeted solutions in order to aid or please specific groups created rivalry in Kerala, undermining collective action, bridging social capital and generalized trust. This argument might be further refined by applying Rothstein's and Stolle's (2008) focus on the institution-centred approach when understanding trust and social capital (generalized trust flourish where there are effective and reliable institutions), and their division between the representational and the implementational side of political institutions. According to this, the basis for trusting political institutions is partisanship - a political party in power is supposed to try to implement its ideology even if parts of the people are against it. According to the authors, this have small consequences for generalized trust. The basis for implementing institutions (e g courts, police force, social services) should however be impartiality - or generalized trust will decrease. While parties in Kerala and Sweden had similar ideologies on a political level, the implementing organizations in Kerala acted as partisans, while they stayed impartial in Sweden, leading to differences in generalized trust. Argument 3: The Rapid Modernization Process in Kerala Leads to Increased Inequalities and Less Civic
Engagement - Which is Hampering Trust

Despite extensive efforts to strengthen collective action and close collaboration between civil society and the state (Veron, 2001; Chathukulam, 2002), inequalities are now rapidly growing in Kerala (Sreeraj \& Vakulabharanam 2015); welfare initiatives have been reduced and the increase in economic growth has since the 1990s been mainly related to the liberalisation of the Indian economy (Harriss \& Törnqvist, 2017). Instead, an extensive remittance economy has been developed, where Keralians leave their homes in order to work in other countries (about $90 \%$ going to the Gulf Countries). Between 1998 and 2014, the number of Kerala emigrants almost doubled (from 1.4 million to 2.4 million), and the remittances that they sent back increased from 2 to 11 billion USD yearly, 36.3 per cent of the Kerala net state domestic product in 2011 (Zachariah \& Irudaya Rajan, 2015).

In all, 3.6 million Keralites - more than one in ten-have lived abroad. Migrants are benefitting from the well-developed education system in Kerala, and are better educated than non-migrants. For every 100 engineers in Kerala, there are 127 Kerala engineers working outside India. Similar patterns are shown for nurses/nursing assistants (85) and sales persons (85) (Zachariah \& Irudaya Rajan, 2015). Roughly speaking, this creates a situation where Kerala is gaining in economic terms (at least in the short run), but is being drained of human capital. In addition, I argue that bridging social capital and generalized trust is eroded through this process. 
When Putnam (2000) discusses the declining American social capital in his famous book "Bowling alone", he says: "We Americans need to reconnect to each other. That is the simple argument of this book. " (p. 28). In his view, civil engagement is essential for building social capital and trust, and he clearly demonstrates the damaging results of its failure. There are reasons to believe that the remittance economy leads to civil disengagement in several ways: real life interaction between people is replaced by money transfers, public engagement and collective action are hampered, and the incitements for creating common goods are replaced by those of consumption and private/in-group welfare solutions.

Rothstein and Uslaner (2005) argue that the key factor underlying trust is the level of equality in a society, more specifically economic equality and the equality of opportunities. As already shown, economic inequality has increased dramatically in Kerala, and Sreeraj and Vakulabharanam (2015) argue that this change can at least in part be traced to the remittance economy (see also Prakash, 1998). The remittance economy has changed the Kerala society in many ways; new opportunities have been created for poor people, while non-migrants have been left behind. For example, Lucose (2005) describes how Non-Residential Indians (NRIs) are becoming middle-class heroes, and are creating new and consumer-oriented (and costly!), westernised lifestyles, adapted but those who have never been outside India. Valatheeswaran (2016) shows that the labour force participation of left behind family members has decreased by $24 \%$ for male members and $46 \%$ for female members.

Concluding the argument; the remittance economy heavily affects Kerala on an individual as well as a structural level, impeding civil engagement and increasing inequality in society. Both these factors has negative effects on social capital and generalized trust.

\section{Concluding Remarks}

When discussing trust, Kerala appears to be a society of contradictions. It is led by communists-who got into power through democratic elections, who implemented reforms to promote equality, and who are today striving for a market economy. It has the most well-developed public welfare system in all India, but also the widest gaps between rich and poor. As these elements - social movements, equality, education, and state capacity-building are important when understanding generalized trust, the existing tensions and contradictories makes Kerala a place of certain interest to study.

Initially, I argue that the collective family situation in Kerala - where joint and extended families are still common - promote particular rather than generalized trust. According to existing research, the "hot" trust with short radius that can be expected to be found in Kerala might have its advantages, but when from a societal capacity-building perspective, the "cool" trust with a long radius is to prefer. One example of this might be found in my other argument. I claim that the communists lost pace when they came into power as they failed to create broad agreements between employers and employees. In trying to please subgroups and specific interests (short radius), they scared away investors - impeding industrial development and economic growth.

In the following, in times characterised by striking mass education and high literacy but modest economic growth, educated people from Kerala migrated, and the world's largest remittance economy was created. Inequalities in society grew dramatically, and remittance money not only created wider gaps between rich and poor, but also increased the belief in private solutions rather than public ones. This was another setback for generalized trust, I argue, as such trust is created through mutual efforts. Moreover, the remittance economy created a situation where family members left behind - to a much larger extent women than men - dropped out of the labour force (reducing their possibilities to build bridging social capital). Moreover, it can be assumed that as when one tenth of the population, most of them better educated, are leaving society during part of their lives, civil engagement and local collective action are hampered.

These arguments have been raised in order to understand the low level of generalized trust in Kerala indicated by the World Value Survey, but also to understand trust and social capital in the well-known Kerala model more generally.

In this society of contradictions, it can be assumed that the improvement of universal welfare policies and broad agreements among the government, the market actors and the civil society are essential for future prosperity. Although there are many striking similarities with the Scandinavian countries, there are also many differences. For further knowledge, trust in Kerala has to be mapped and discussed, not only to understand the situation in this specific Indian state, but also in order to add to existing theories of trust, often developed in wealthy, well-developed Western societies.

\section{References}

Bank, W. (2016). Mortality rate, infant (per 1,000 live births). Retrieved from 
https://data.worldbank.org/indicator/SP.DYN.IMRT.IN

Commissioner, O. o. t. R. G. C. (2015). Household Assets 2011. Retrieved from https://www.census2011.co.in/hhassets.php

Delhey, J., Newton, K., \& Welzel, C. (2011). How general is trust in "most people"? Solving the radius of trust problem. American Sociological Review, 76(5), 786-807. https://doi.org/10.1177/0003122411420817

Development, O. f. E. C.-o. a. (2015). OECD Income inequality data update: Sweden (January 2015). Retrieved from http://www.oecd.org/sweden/OECD-Income-Inequality-Sweden.pdf

Dreze, J., \& Sen, A. (2002). India: Development and participation. Oxford University Press, USA. https://doi.org/10.1093/acprof:oso/9780199257492.001.0001

Fukuyama, F. (1995). Trust: The social virtues and the creation of prosperity. Free Press Paperbacks.

Harriss, J., \& Törnquist, O. (2015). Comparative Notes on Indian Experiences of Social Democracy: Kerala and West Bengal. Centre for Socio-Economic \& Environmental Studies.

Harriss, J., \& Törnquist, O. (2015). Comparative Notes on Indian Experiences of Social Democracy: Kerala and West Bengal (SWP 39).

Heller, P. (1999). The labor of development: Workers and the transformation of capitalism in Kerala. India: Cornell University Press.

Heller, P. (2001). Moving the state: the politics of democratic decentralization in Kerala, South Africa, and Porto Alegre. Politics \& Society, 29(1), 131-163. https://doi.org/10.1177/0032329201029001006

ICF, I. I. f. P. S. I. a. (2017). National Family Health Survey (NFHS-4) India 2015-16 Kerala. Retrieved from http://rchiips.org/NFHS/NFHS-4Reports/Kerala.pdf

Inglehart, R., \& Welzel, C. (2010). Changing mass priorities: The link between modernization and democracy. Perspectives on Politics, 8(2), 551-567. https://doi.org/10.1017/S1537592710001258

John, M., \& Chathukulam, J. (2002). Building social capital through state initiative: participatory planning in Kerala. Economic and Political Weekly, 1939-1948.

Karlsson, M. (Forthcoming). Welfare in Growing Pains: The Quest for Understanding Happiness in Kerala. In.

Kenny, P. D. (2015). Colonial rule, decolonisation, and corruption in India. Commonwealth \& Comparative Politics, 53(4), 401-427. https://doi.org/10.1080/14662043.2015.1089002

Kettunen, P. (2014). Conflicts and compromises in the Nordic pattern of social regulation. Reshaping Welfare Institutions in China and the Nordic Countries, Helsinki: NordWel, 96-121.

Khan, M. I., \& Valatheeswaran, C. (2016). International migration, remittances and labour force participation of left-behind family members: A study of Kerala. Margin: The Journal of Applied Economic Research, 10(1), 86-118. https://doi.org/10.1177/0973801015612669

Kulke, H., \& Rothermund, D. (2010). A history of India. London: Routledge.

Leung, A., Kier, C., Fung, T., Fung, L., \& Sproule, R. (2011). Searching for happiness: The importance of social capital. Journal of Happiness Studies, 12(3), 443-462. https://doi.org/10.1007/s10902-010-9208-8

Lukose, R. (2005). Consuming globalization: Youth and gender in Kerala, India. Journal of Social History, 38(4), 915-935. https://doi.org/10.1353/jsh.2005.0068

Lundåsen, S. W., \& Trägårdh, L. (2013). Social Trust and Religion in Sweden: Theological Belief Versus Social Organization. In Religion and Civil Society in Europe (pp. 109-124): Springer.

Lundström, T., \& Svedberg, L. (2003). The voluntary sector in a social democratic welfare state-The case of Sweden. Journal of Social policy, 32(2), 217-238. https://doi.org/10.1017/S0047279402007006

Lundström, T., \& Wijkström, F. (1995). Från röst till service?: den svenska ideella sektorn i förändring. Sköndal: Sköndalsinstitutet.

Musiał, K. (1999). Institutionalisation of Scandinavian consensual democracy.

Newton, K., \& Zmerli, S. (2011). Three forms of trust and their association. European Political Science Review, 3(2), 169-200. https://doi.org/10.1017/S1755773910000330

Niranjan, S., Nair, S., \& Roy, T. (2005). A socio-demographic analysis of the size and structure of the family in India. Journal of Comparative Family Studies, 623-651. 
Onyx, J., \& Bullen, P. (2000). Measuring social capital in five communities. The journal of applied behavioral science, 36(1), 23-42. https://doi.org/10.1177/0021886300361002

Ostrom, E., \& Ahn, T.-K. (2009). The meaning of social capital and its link to collective action. Handbook of social capital. The troika of sociology, political science and economics, 17-35. https://doi.org/10.4337/9781848447486.00008

Portes, A. (2000). The two meanings of social capital. Paper presented at the Sociological forum. https://doi.org/10.1023/A:1007537902813

Prakash, B. (1998). Gulf migration and its economic impact: The Kerala experience. Economic and Political Weekly, 3209-3213.

Putnam, R. D. (1995). Tuning in, tuning out: The strange disappearance of social capital in America. PS: Political Science \& Politics, 28(4), 664-684. https://doi.org/10.1017/S1049096500058856

Putnam, R. D. (2000). Bowling alone: America's declining social capital. In Culture and politics (pp. 223-234). Springer.

Riley, P., \& Roy, R. K. (2016). Corruption and anticorruption: the case of India. Journal of Developing Societies, 32(1), 73-99. https://doi.org/10.1177/0169796X15609755

Rothstein, B. (2011). Anti-corruption: The indirect 'big bang' approach. Review of International Political Economy, 18(2), 228-250. https://doi.org/10.1080/09692291003607834

Rothstein, B., \& Stolle, D. (2002). How political institutions create and destroy social capital: An institutional theory of generalized trust. Paper presented at the delivery at the Annual Meeting of the American Political Science Association, Boston, August-September.

Rothstein, B., \& Stolle, D. (2008). The state and social capital: An institutional theory of generalized trust. Comparative politics, 40(4), 441-459. https://doi.org/10.5129/001041508X12911362383354

Rothstein, B., \& Teorell, J. (2008). What is quality of government? A theory of impartial government institutions. Governance, 21(2), 165-190. https://doi.org/10.1111/j.1468-0491.2008.00391.x

Rothstein, B., \& Uslaner, E. M. (2005). All for all: Equality, corruption, and social trust. World politics, 58(1), 41-72. https://doi.org/10.1353/wp.2006.0022

Sreeraj, A. P., \& Vakulabharanam, V. (2016). High growth and rising inequality in Kerala since the 1980s. Oxford Development Studies, 44(4), 367-383. https://doi.org/10.1080/13600818.2015.1111320

Steijn, S., \& Lancee, B. (2011). Does income inequality negatively affect general trust. Examining three potential problems with the inequalitytrust hypothesis.

Sundström, G. (2014). Så bor och lever Sverige. Välfärd(1/2014).

Suryanarayana, M. H., Ankush Agrawal, \& Seeta, P. (2011). Inequality-adjusted human development index for India's states.

Svensson, T. (2017). Strengthening Control or Fostering Trust? Indian Politics and Scandinavian Experiences. In O. a. F. E. Törnquist (Ed.), Reinventing Social Democratic Development: Insights from Indian and Scandinavian Comparisons (pp. 168-188). New Dehli: Manohar.

Sztompka, P. (1999). Trust: A sociological theory. Cambridge University Press.

Tanzi, V. (1998). Corruption around the world: Causes, consequences, scope, and cures. Staff Papers, 45(4), 559-594. https://doi.org/10.2307/3867585

Trägårdh, L. (2013). The historical incubators of trust in Sweden: from the rule of blood to the rule of law. In Trust and Organizations (pp. 181-203). Springer. https://doi.org/10.1057/9781137368812_10

Uslaner, E. M., \& Rothstein, B. (2016). The historical roots of corruption: state building, economic inequality, and mass education. Comparative politics, 48(2), 227-248. https://doi.org/10.5129/001041516817037736

van Hoorn, A. (2014). Trust Radius versus Trust Level: Radius of Trust as a Distinct Trust Construct. American Sociological Review, 79(6), 1256-1259. https://doi.org/10.1177/0003122414555398

Van Oorschot, W., Arts, W., \& Gelissen, J. (2006). Social capital in Europe: Measurement and social and regional distribution of a multifaceted phenomenon. Acta sociologica, 49(2), 149-167. https://doi.org/10.1177/0001699306064770

Véron, R. (2001). The "new" Kerala model: Lessons for sustainable development. World development, 29(4), 
601-617. https://doi.org/10.1016/S0305-750X(00)00119-4

Wollebaek, D., Lundåsen, S. W., \& Trägårdh, L. (2012). Three forms of interpersonal trust: evidence from $\begin{array}{lllll}\text { Swedish } & \text { municipalities. }\end{array}$ https://doi.org/10.1111/j.1467-9477.2012.00291.x

Zachariah, K. C. (2017). Changing Kerala: Population Growth \& Economic Development of Religious Denominations. Trivandrum: Nalanda Books.

Zachariah, K. C., \& Rajan, S. I. (2015). Dynamics of emigration and remittances in Kerala: Results from the Kerala migration survey 2014. Centre for Development Studies Thiruvananthapuram.

\section{Copyrights}

Copyright for this article is retained by the author(s), with first publication rights granted to the journal.

This is an open-access article distributed under the terms and conditions of the Creative Commons Attribution license (http://creativecommons.org/licenses/by/4.0/). 